\title{
Evaluation of suspended particulate matter (SPM) around municipal solid waste dumpsites in yenagoa metropolis, Nigeria
}

\begin{abstract}
This research investigated the spatial and seasonal impacts of Suspended Particulate Matter (SPM), associated with 4 Household Municipal Solid Wastes dumpsites (MSWs), and two stations in the central MSWs dumpsite in Yenagoa Metropolis. The SPM values were monitored at levels PM1, PM2.5, PM4, PM7, PM10 and Total Suspended Particulate. Comparatively, concentration of SPM at PM1 was $17.04 \pm 0.70-32.81 \pm 2.80 \mu \mathrm{g} / \mathrm{m} 3$ in dry season and $14.03 \pm 0.15-19.03 \pm 2.57 \mu \mathrm{g} / \mathrm{m} 3$ in wet season $(\mathrm{p}<0.05)$. At level of PM2.5 SPM was $23.11 \pm 0.96-44.87 \pm 5.97$ and $20.41 \pm 0.52-32.07 \pm 3.35 \mu \mathrm{g} / \mathrm{m} 3$ respectively. Other levels of SPM in Dry/Wet Season were reported for: PM4 $(32.03 \pm 3.5262 .80 \pm 6.85 / 29.82 \pm 2.2650 .54 \pm 5.17 \mu \mathrm{g} / \mathrm{m} 3)$, PM7 $(75.01 \pm 4.90197 .11 \pm 8.90 / 45.17 \pm 5.26-71.27 \pm 7.11 \mu \mathrm{g} / \mathrm{m} 3$ and PM10 $(109.40$ $\pm 7.69-305.10 \pm 8.36 / 56.53 \pm 5.18-93.07 \pm 4.50 \mu \mathrm{g} / \mathrm{m} 3)$ with significant difference $(\mathrm{p}<0.05)$. Furthermore, the levels of TSP in dry season was higher and ranged from $227.66 \pm 9.36-597.26 \pm 9.63 \mu \mathrm{g} / \mathrm{m} 3$ compared to values of $72.40 \pm 1.25-172.23 \pm 6.25 \mu \mathrm{g} /$ $\mathrm{m} 3$ in dry season $(\mathrm{p}<0.05)$. Based on interpretations from calculation of Air Quality Index; Dumpsites in Mopol base and Kpansia market were polluted in dry season and fairly clean in wet season. Etegwe and Opolo market dumpsites are heavily polluted in dry season and fairly clean in wet season. Unfortunately, the two sampling stations in the central dumpsites were severely polluted in dry season but moderately polluted in wet season. Reckless disposal of uncharacterized and untreated MSWs pose adverse effects to the environment and public health. We therefore urge the populace to desist from reckless disposal of MSWs on one hand, and urge Government to formulate policies the will effective reduce, reuse and recycling MSW, as well as the treatment needless fractions of MSW prior to their disposal.
\end{abstract}

Keywords: particulate matter, waste stream, anthropogenic activity, municipal solid waste, yenagoa metropolis
Volume 4 Issue 2 - 2018

\section{Tariwari Chidi Angaye, Jasper Freeborn Nestor Abowei \\ Department of Biological Science, Niger Delta University, Nigeria}

Correspondence: Tariwari C.N Angaye, Department of Biological Science, Faculty of Science, Niger Delta University, Wilberforce Island, Bayelsa State, Nigeria,

Emailmaktarry@yahoo.com

Received: February 09, 2018 | Published: March 13, 2018

\section{Introduction}

Landfilling has become the commonest and most common and economically viable method of disposing MSWs that cannot be reduced, reuse or recycled. However, that strategy for landfilling in most developing nation is below global best practices Angaye \& Abowei et al. ${ }^{1}$ For instance, it has even become worrisome that prior to disposal, most waste streams generated are not segregated or treated in order to eliminate their toxic components. Also, poor funding leaves the government with just the option of catering for the transportation and disposal of MSWs to their targeted dumpsites or landfill with huge and unattended waste streams. Furthermore, attempt to reduce these piles of waste streams results in their in situ burning emitting toxic gases and suspended particulates that infringe on ambient air quality.

Air pollution is introduction of gaseous or suspended particulate matter into the atmosphere, that infringes on the ambient air quality. It can be as a result of natural or anthropogenic activities in the environment as such ambient air quality of any place is usually determined by the extent of pollution. ${ }^{2-4}$ The emission of air pollutants poses adverse impact on public health and the ecosystem as most biotas have the ability to bioaccumulate them via food chain or directly through the body orifices via the nasal cavity.

According to Metz et $a .^{5}$ when organic components of MSW decomposes the emission of some harmful gases consisting of 50$60 \%$ methane, $30-40 \%$ carbon dioxide, and $2 \%-9 \%$ of other gases are released to the atmosphere and as well as heavy metals. ${ }^{6}$ Oxides of sulphur $\left(\mathrm{SO}_{\mathrm{X}}\right)$ and Nitrogen $\left(\mathrm{NO}_{\mathrm{X}}\right)$ can cause lung and cardiovascular ailments, while Suspended Particulate Matter have been reported to cause asthma, bronchitis, lung cancer, cardiovascular disease, birth defect and premature death US-EPA \& Rim-Rukeh et al., ${ }^{7,8}$ Other air pollutants include but not limited to: Carbon monoxide (CO), Methane (CH4), Ammonia (NH3), Hydrogen Sulphide $\left(\mathrm{H}_{2} \mathrm{~S}\right)$ etc. Some pollutants like methane are colourless and invisible, pollutant like SPM are visible including dust, sooth etc.

Statistic documented in literature has established that; $80 \%$ of untimely mortality associated to air pollution results to heart disease and stroke, while $14 \%$ are results to chronic obtrusive pulmonary disease or acute respiratory infections, and $6 \%$ results to lung cancer. ${ }^{2}$ On annual basis, most cities utilize $20-50 \%$ of their budget on the 
management of MSWs, with only $20-80 \%$ of waste collection Ayuba et al. ${ }^{9}$ Unfortunately, in most cases piles of unattended waste are seen all some over some cities for days with the envisaged risk of environmental pollution of ambient air quality. These wastes are transformed biologically by microbes or chemically by burning thereby emitting toxic respirable components to all forms of biota. As such the Evaluation of Suspended Particulate Matter (SPM) Around Municipal Solid Waste Dumpsites in Yenagoa Metropolis has become necessary. ${ }^{10}$

\section{Methodology}

\section{Sampling sites}

Seven (7) Municipal Solid Waste dumpsites including control were investigated for the case of this study, in both wet and dry seasons. Geo-referencing of each sampling station during the data gathering was achieved with the aid of a hand Global Positioning System (GPS), Germin etrex GPS (model CZ 99052-20-Taiwan).

\section{Sampling procedures}

In the Municipal Solid Waste dump sites, six (6) SPM monitoring parameters; PM1, PM2.5, PM4, PM7, PM10 and Total suspended particulate (TSP), were determined Vusing hand-held SPM meter

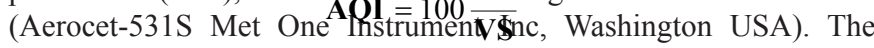
monitor uses light scatter to measure individual particles instead of clouds like other monitors. The particle information is then grouped into size ranges and converted to mass concentration over 4 minutes at a flow rate of $2.83 \mathrm{~L} / \mathrm{min}$ into measuring ranges of: $1-10$ micrograms per cubic metre mass concentration. Measurements was done by holding the sensor to a height of about two meters in the direction of the prevailing wind and readings recorded at stability. The study was carried out dry (November, January and March) and wet (May, July and September) seasons in a post-monthly manner, from November 2016 through September 2017.

\section{Air quality index (AQI)}

The Air Quality Index is a scheme developed to scale the magnitude of air pollution by pollutant gases or particulate matter suspended in the atmosphere. The recorded concentrations of air pollutants are usually calculated to the AQI index using the universal formulae below and interpreted as described in below, values emerging were interpreted as presented in Table 1.

Where V is recorded concentration of pollutant gas VS is National Regulatory Limit for the individual pollutant gas

Table I Scheme for assessment of Air Quality Index

\begin{tabular}{lll}
\hline Index categories & $\begin{array}{l}\text { Index } \\
\text { magnitude }\end{array}$ & Impact classification \\
\hline A & $<10$ & Very clean \\
B & $>10-25$ & Clean \\
C & $>25-50$ & Fairly Clean \\
D & $>50-75$ & Moderately polluted \\
E & $>75-100$ & Polluted \\
F & $>100-125$ & Heavily polluted \\
G & $>125$ & Severely Polluted \\
\hline
\end{tabular}

\section{Statistical analysis}

All results are expressed as Mean \pm Standard Deviation. Analysis of variance was carried out. The applied Post-Hoc was used to establish differences was Duncan's multiple range test $(\mathrm{P}<0.05)$. The Mean data were used to plot charts using Microsoft excel (2013 version).

\section{Result and discussion}

Figure 1 presents the results of Suspended Particulate Matter (SPM) of the MSWs at the level of Particulate Matter 1 (PM1). Results showed that in dry season PM1 ranges from 17.04 $\pm 0.70-32.81 \pm 2.80 \mu \mathrm{g} /$ $\mathrm{m}^{3}$, being significantly different compared to the control $(\mathrm{p}<0.05)$. With exception of dumpsites in Mopol base and Etegwe there was significant differences $(p<0.05)$ amongst the dumpsites in dry season. The highest value of PM1 in dry season was recorded in the second station of the central dumpsite (CDS 2), while the lowest value was recorded in the dumpsite located in Kpansia market. Comparatively, the values of PM1 in wet season, which was relatively lower ranged from $14.03 \pm 0.15-19.03 \pm 2.57 \mu \mathrm{g} / \mathrm{m}^{3}(\mathrm{p}<0.05)$. The highest and lowest values of PM1 in wet season was similarly indicated in CDS 2 and Kpansia market dumpsites respectively, with PM 1 values of dumpsites in Mopol base and Etegwe being statistically different $(\mathrm{P}<0.05)$ compared to other stations (Figure 1). As presented in Figure 2, results of SPM at the level of PM 2.5 in dry season ranged from $23.11 \pm 0.96-$ $44.87 \pm 5.97 \mu \mathrm{g} / \mathrm{m}^{3}$. Besides dumpsites in Opolo and Kpansia markets, there was significant difference amongst all sampling stations in dry season $(p<0.05)$. The second sampling station of the central dumpsite recorded the highest value compared to Kpansia market which was lowest, but not statistically lower than the control $(\mathrm{p}<0.05)$. On the other hand, values of PM2.5 in wet season ranged from $20.41 \pm 0.52$ $32.07 \pm 3.35 \mu \mathrm{g} / \mathrm{m}^{3}$. Besides values of the central dumpsites (CDS 1 and CDS 2), there was no significant difference amongst other sampling stations $(p>0.05)$. Notwithstanding, while the control value was lowest $(p<0.05)$, the second station of the central dumpsite has the highest value, while dumpsite in Kpansia market has the lowest value. Generally, PM2.5 values of dry season were relatively higher than wet season $(p<0.05)$. Figure 3 presents the results of spatial and seasonal variations of SPM at level PM 4. Results showed that PM4 ranged from $32.03 \pm 3.52-62.80 \pm 6.85 \mu \mathrm{g} / \mathrm{m}^{3}$. While the control station was lowest with significant difference $(p<0.05)$, the dumpsites in Etegwe and Opolo markets were statistically similar ( $p>0.05)$, but significantly different when compared to other dumpsites $(p<0.05)$. The highest value of PM4 was indicated in the second station of the central dumpsite, and the lowest in Kpansia market. In the wet season PM4 ranged from $29.82 \pm 2.26-50.54 \pm 5.17 \mu \mathrm{g} / \mathrm{m}^{3}$, with no significant difference amongst the dumpsites except for the central dumpsites ( $p>0.05$ ). In addition, the second station of the central dumpsite had the highest value, while dumpsite located in Mopol base had the lowest value. Generally, it was noteworthy that values of PM4 were significantly higher in dry season compared to dry season $(p<0.05)$. Figure 4 demonstrates values of SPM at level of PM7 in both dry and wet season. Results showed that PM7 in dry season ranged from $75.01 \pm 4.90-197.11 \pm 8.90 \mu \mathrm{g} / \mathrm{m}^{3}$. Meanwhile, besides dumpsites in Etegwe and Opolo market there was significant difference in terms of dry season values of PM7 amongst the dumpsites $(p<0.05)$. Invariably, the highest value of PM7 was recorded in the first station of the central dumpsite, while the lowest value was indicated in Kpansia market. On the other hand, PM7 values of the dumpsites in wet season ranged from $45.17 \pm 5.26-71.27 \pm 7.11 \mu \mathrm{g} / \mathrm{m}^{3}$ with no significant difference ( $p>0.05$ ), except for the central dumpsites (CDS 1 and 2). The highest value of PM7 in wet season was reported in second station of the central dumpsite (CDS 2), and the lowest value in Mopol base dumpsite located at Etegwe. The PM7 values of dry season were significantly higher than values of wet season $(p<0.05)$. Figure 5 presents the SPM values at level of PM10 of the MSW, amongst the sampling stations and between the seasons. Results showed that PM10 ranged from $109.40 \pm 7.69-305.10 \pm 8.36 \mu \mathrm{g} / \mathrm{m}^{3}$ in dry season with significant difference $(\mathrm{p}<0.05)$, amongst the sampling station 
except for dumpsites in Mopol base and Opolo market. While the control station was significantly lowest, the highest PM10 value was recorded in the first station of the central dumpsite (CDS 1), and the lowest value reported in Opolo market dumpsite. Comparatively, in wet season PM10 value ranges from $56.53 \pm 5.18-93.07 \pm 4.50 \mu \mathrm{g} /$ $\mathrm{m}^{3}$. Furthermore, Mopol base and Etegwe dumpsites where not statistically different ( $>0.05$ ), but dissimilar when compared to Opolo and Kpansia markets as well as the first and second stations of the central dumpsite $(\mathrm{p}<0.05)$. It is also worthy of note that PM10 values of dry season were statistically higher and different compared to values of wet season $(\mathrm{p}<0.05)$. Figure 6 demonstrates the levels of Total Suspended Particulate matter (TSP) of the MSW dumpsites in both dry and wet seasons. The values of TSP ranged from $227.66 \pm 9.36-597.26 \pm 9.63 \mu \mathrm{g} / \mathrm{m}^{3}$, with significant differences amongst all sampling stations, except for dumpsites in Mopol base and Kpansia market $(\mathrm{p}<0.05)$. The highest value of TSP associated with the dumpsites in dry season was recorded in first station of the central dumpsite, and the lowest value indicated in the dumpsite located in Kpansia market. On the other hand, TSP values of the wet season ranged from $72.40 \pm 1.25-172.23 \pm 6.25 \mu \mathrm{g} / \mathrm{m}^{3}$. Furthermore, with exception to dumpsites in Mopol base and Opolo market which were statistically similar ( $p>0.05)$, there was significant difference amongst the sampling stations in terms of TSP values $(p<0.05)$. Notwithstanding, highest value of TSP was recorded in the first station of the central dumpsite and lowest value in Etegwe dumpsite. The recommended TSP value by the Nigerian Federal Ministry of Environment is $\leq 250 \mu \mathrm{g} / \mathrm{m}^{3} / 24$ hours, based on air quality index (AQI) calculation; dumpsite in Mopol base and Kpansia market dumpsites were polluted in dry season and fairly clean in wet season. Etegwe and Opolo market dumpsites are heavily polluted in dry season and fairly clean in wet season. The two sampling stations in the central dumpsites were severely polluted in dry season but moderately polluted in wet season.

In tandem with our present study was an Assessment of Municipal Solid Waste Dump Sites in Delta state showed that the level of SPM at PM10 ranges from $773-801 \mu \mathrm{g} / \mathrm{m}^{3}$ which was highest amongst all MSWs pollutant gases, exceeding the regulatory limit of the Federal Ministry of Environment. ${ }^{8}$ Our result is also comparable with values obtained for dumpsites in Port-Harcourt using Particulate analyser at micron levels; PM0.3 $\left(25.50-58.26 \mu \mathrm{g} / \mathrm{m}^{3}\right)$, PM0.5 $(1.61-8.48$ $\left.\mu \mathrm{g} / \mathrm{m}^{3}\right)$, PM1.0 $\quad\left(0.35-0.66 \mu \mathrm{g} / \mathrm{m}^{3}\right), \quad$ PM2.0 $\quad\left(0.16-1.31 \mu \mathrm{g} / \mathrm{m}^{3}\right)$ and PM5.0 was in the range of $2.61-11.96 \mu \mathrm{g} / \mathrm{m}^{3}{ }^{6}$ A study on the Evaluation of The On-Site and Off-Site Ambient Air Quality at Nekede Waste Dumpsite, Imo State, Nigeria recorded PM10 values in the range of $6.30-6.80$ and $6.00-6.40 \mathrm{ppm}$ in the morning and evening respectively. In the same study, values recorded $100(6.20$ $6.70 \mathrm{ppm})$, and 200 metres (5.60-6.01 ppm) away from the dumpsite were also reported in the study. ${ }^{2}$ Another author in India, reported high level of SPM in dumpsite for pre-monsoon season (May) to be $429.4 \mu \mathrm{g} / \mathrm{m}^{3}$ compared to post monsoon (November) with values in the range of $156.60-198.50 \mu \mathrm{g} / \mathrm{m}^{3}$. Results of this study raise concern as inhalation of SPM from MSWs can cause grave pulmonary adverse effects. Worker obligated to work around such vicinity should adhere to safety conditions by using appropriate PPEs. High level of SPM in the dumpsites could be attributed suspended smoke originating from the dumpsites due to uncontrolled open air burning of MSW which was similarly reported Rim-Rukeh et al. ${ }^{8}$ Seasonality also play a great role in variability of SPM, lower level of SPM in wet season is largely due to sequestrations of particulate matter by moisture content due to high level of relative humidity. Higher temperature in dry season, which is dusty and windy seems to increase the mobility of SPM. Variation is spatial values is a reflection of the levels of anthropogenic activities in the sampling stations.

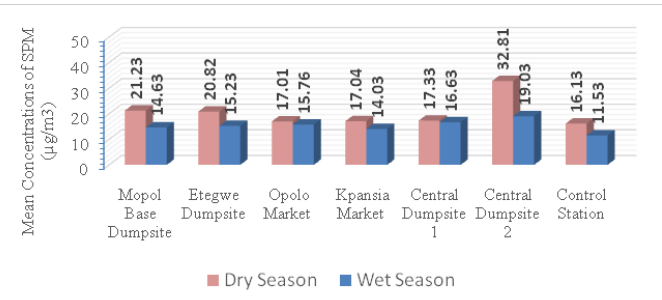

Figure I Mean Spatial and Seasonal concentrations of Suspended Particulate Matter at PMI

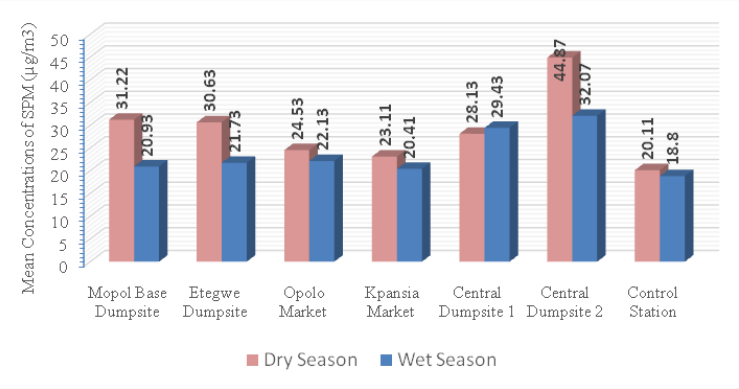

Figure 2 Mean Spatial and Seasonal concentrations of Suspended Particulate Matter at PM2.5.

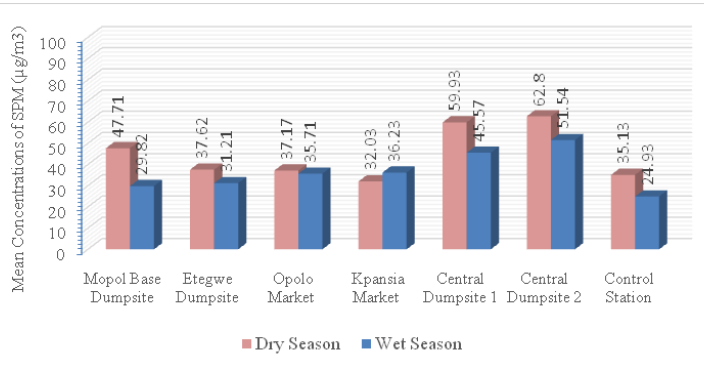

Figure 3 Mean Spatial and Seasonal concentrations of Suspended Particulate Matter at PM4.

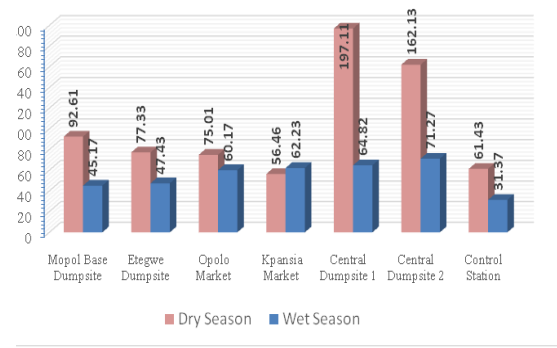

Figure 4 Mean Spatial and Seasonal concentrations of Suspended Particulate Matter at PM7.

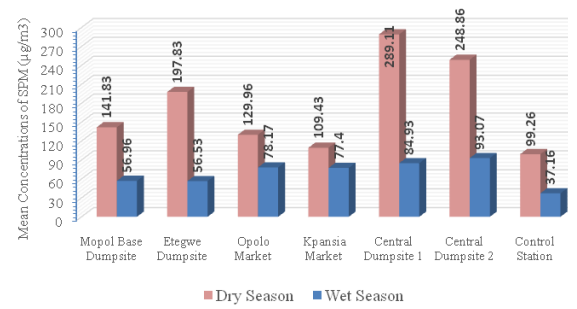

Figure 5 Mean Spatial and Seasonal concentrations of Suspended Particulate Matter at PMIO. 


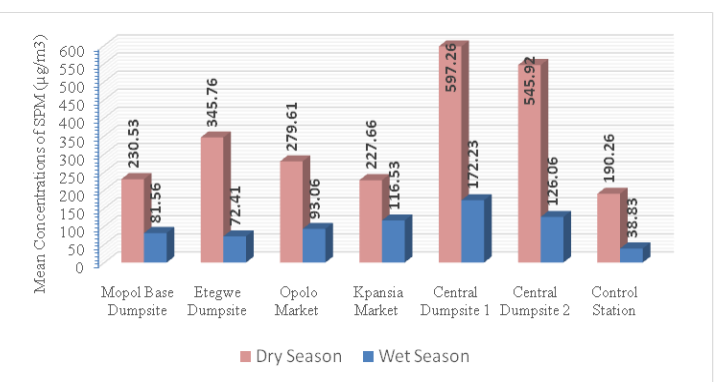

Figure 6 Mean Spatial and Seasonal concentrations of Total Suspended Particulate Matter.

with MSWs.

\section{Acknowledgment}

This research is based on the dissertation of Mr. Tariwari C.N Angaye Supervised by Prof. Abowei JFN.

\section{Conflict of interests}

The authors have declared that no competing interests exist.

\section{References}

1. Angaye TCN, Abowei JFN. Review on the Environmental Impacts of Municipal Solid Waste in Nigeria: Challenges and Prospects. Greener Journal of Environmental Management and Public Safety. 2017;6(2):18-33.

2. Ubouh EA, Nwawuike N, Ikwa L, et al. Evaluation of the On-Site and Off-Site Ambient Air Quality (Aaq) At Nekede Waste Dumpsite, Imo State, Nigeria. British Journal of Earth Sciences Research. 2016;4(1):18-22.

3. Ubuoh EA, Akhionbare SMO. "Effects of Pig Production on Ambient Air Quality of Egbeada in Mbaitoli Local Government area of Imo State, Nigeria". Journal of Sciences and Multidisciplinary Research (JSMR). 2011;3:8-16.

4. Agwu A, Ozeh RN. Evolution of Ambient Air. Quality of Aba Metropolis, Nigeria. International Journal of Current Research.

\section{Conclusion}

This study evaluated the spatial and seasonal levels of SPM in Yenagoa Metropolis. Unfortunately, results showed that significant levels of particulate matter amongst the sampling stations. Higher levels of SPM exceeding regulatory limits were observed in dry season compared to wet season, with the central dumpsite having the highest value. The concentration of SPM in the control station was found to be lowest compared to other MSW stations. The SPM individually poses adverse health risks, or in synergy with other gaseous pollutants like, Carbon monoxide, methane, Hydrogen Sulphide, as well as Oxides of Sulphur and Nitrogen. As such, this pollutant has become a major source of concern to the environment and public health, as there is need to consistently monitor the level of pollutants associated

$$
\text { 2013;5(4):843-844. }
$$

5. Metz B, Davidson OR, Bosch PR, et al. Contribution of Working Group III to the Fourth Assessment Report of the Intergovernmental Panel on Climate Change. New York: Cambridge University Press; 2007.

6. Ezekwe CI, Agbakoba C, Igbagara PW, et al. Source Gas Emission and Ambient Air quality around the Eneka co-disposal landfill in Port-harcourt, Nigeria. International Journal of Applied Chemistry and Industrial Sciences. 2016;2(1):11-23.

7. US EPA. National Emission Standards for Hazardous Air Pollutants for Source Categories. Cement Manufacturing Industries Federal Register. 1999;64:113.

8. Rim Rukeh A. An Assessment of the Contribution of Municipal Solid Waste Dump Sites Fire to Atmospheric Pollution. Journal of Air Pollution. 2014;3(3):53-60.

9. Ayuba KA, Abd Manaf L, Sabrina AH, et al. Current Status of Municipal Solid Waste Management Practise in FCT Abuja. Research Journal of Environmental and Earth Sciences. 2013;5(6):295-304.

10. Ubuoh EA, Akhionbare SMO. Effects of Pig Production on Ambient Air Quality of Egbeada in Mbaitoli Local Government area of Imo State, Nigeria". Journal of Sciences and Multidisciplinary Research Nigeria. 2011;3:8-16. 